\title{
Intraoperative Fractions of Inspiratory Oxygen Are Associated With Recurrence-Free Survival After Elective Cancer Surgery
}

\begin{abstract}
Sarah Dehne ${ }^{1}$, Verena Spang ${ }^{1}$, Rosa Klotz ${ }^{2}$, Laura Kummer ${ }^{1}$, Samuel Kilian ${ }^{3}$, Katrin Hoffmann ${ }^{2}$, Martin A. Schneider ${ }^{2}$, Thilo Hackert ${ }^{2}$, Markus W. Büchler ${ }^{2}$, Markus A. Weigand ${ }^{1}$ and Jan Larmann ${ }^{1 *}$
\end{abstract}

${ }^{1}$ Department of Anesthesiology, University Hospital Heidelberg, Heidelberg, Germany, ${ }^{2}$ Department of General, Visceral and Transplantation Surgery, University Hospital Heidelberg, Heidelberg, Germany, ${ }^{3}$ Institute of Medical Biometry, University Heidelberg, Heidelberg, Germany

Background: Choice of the fraction of inspiratory oxygen $\left(\mathrm{FiO}_{2}\right)$ is controversial. The objective of this analysis was to evaluate whether intraoperative $\mathrm{FiO}_{2}$ was associated with recurrence-free survival after elective cancer surgery.

Methods and Analysis: In this single-center, retrospective study, we analyzed 1,084 patients undergoing elective resection of pancreatic $(n=652)$, colorectal $(n=405)$, or hepatic cancer $(n=27)$ at Heidelberg University Hospital between 2009 and 2016. Intraoperative mean $\mathrm{FiO}_{2}$ values were calculated. For unstratified analyses, the study cohort was equally divided into a low- and a high- $\mathrm{FiO}_{2}$ group. For cancer-stratified analyses, this division was done within cancer-strata. The primary outcome measure was recurrence-free survival until the last known follow-up. Groups were compared using Kaplan-Meier analysis. A stratified log rank test was used to control for different $\mathrm{FiO}_{2}$ levels and survival times between the cancer strata. Cox-regression analyses were used to control for covariates. Sepsis, reoperations, surgical-site infections, and cardiovascular events during hospital stay and overall survival were secondary outcomes.

Results: Median $\mathrm{FiO}_{2}$ was $40.9 \%$ (Q1-Q3, 38.3-42.9) in the low vs. 50.4\% (Q1-Q3, 47.4-54.7) in the high- $\mathrm{FiO}_{2}$ group. Median follow-up was 3.28 (Q1-Q3, 1.68-4.97) years. Recurrence-free survival was considerable higher in the high- $\mathrm{FiO}_{2}$ group $(p<0.001)$. This effect was also confirmed when stratified for the different tumor entities $(p=0.007)$. In colorectal cancer surgery, increased $\mathrm{FiO}_{2}$ was independently associated with increased recurrence-free survival. The hazard for the primary outcome decreased by $3.5 \%$ with every $1 \%$ increase in $\mathrm{FiO}_{2}$. The effect was not seen in pancreatic cancer surgery and we did not find differences in any of the secondary endpoints.

Conclusions: Until definite evidence from large-scale trials is available and in the absence of relevant clinical conditions warranting specific $\mathrm{FiO}_{2}$ values, perioperative care givers should aim for an intraoperative $\mathrm{FiO}_{2}$ of $50 \%$ in abdominal cancer surgery as this might benefit oncological outcomes.

Keywords: supplemental oxygen therapy, postoperative complications, perioperative management, oxygen related effects, recurrence-free survival 


\section{INTRODUCTION}

An increased fraction of inspiratory oxygen $\left(\mathrm{FiO}_{2}\right)$ is frequently used in anesthesia, intensive care, and emergency medicine. A concept of using 80 vs. $30 \% \mathrm{FiO}_{2}$ has been proposed for the prevention of surgical site infections (SSI) more than 20 years ago (1) and has been evaluated in several subsequent randomized controlled trials (RCTs) (1-3). Based on a systematic review and meta-analysis (4), the WHO and other societies (5-7) issued guidelines advocating the use of $80 \% \mathrm{FiO}_{2}$ during surgery. These recommendations have caused considerable concern, as the authors of other systematic reviews and meta-analyses arrive at opposing conclusions $(8,9)$ and because the relevance of potential oxygen-mediated side effects is still under debate $(9,10)$. In a post-hoc analysis of the PROXI trial, administration of $80 \%$ oxygen in the perioperative period was associated with increased long-term mortality in patients undergoing cancer surgery (11), and after a median follow-up of 3.9 years, cancer-free survival was significantly reduced in the $80 \%$ oxygen group compared with patients randomized to $30 \% \mathrm{FiO}_{2}$ (12). Outside of clinical trials and before the first $\mathrm{WHO}$ recommendation regarding supplemental oxygen (13) was published, intraoperative $\mathrm{FiO}_{2}$ was typically used in the range of $30 \%$ to more than $90 \%$, and the choice for the actual $\mathrm{FiO}_{2}$ did depend on patients' requirements, type of surgical intervention, and anesthesiologist's preferences (14).

Currently, it is unknown whether the choice of higher or lower $\mathrm{FiO}_{2}$ in a real-world setting outside of clinical trials is associated with long-term outcomes after cancer surgery. Therefore, we conducted a retrospective and exploratory study to evaluate the association of perioperative $\mathrm{FiO}_{2}$ and recurrencefree survival after elective cancer surgery was performed before the WHO recommendation advocating supplemental oxygen for prevention of SSI was published.

\section{METHODS}

\section{Study Design and Population}

We performed a retrospective and exploratory study in patients receiving general anesthesia for elective abdominal cancer surgery in the period from January 1, 2009, to December 31, 2016, at the Department of General-, Visceral-, and Transplant Surgery, Heidelberg University Hospital, Heidelberg, Germany. The study protocol conformed to the "Strengthening the Reporting of Observational studies in Epidemiology (STROBE)" guidelines (15), and the principles of the Declaration of Helsinki

\footnotetext{
Abbreviations: ASA, American Society of Anesthesiologists physical status classification; B, Coefficient of variable; BMI, Body Mass Index; COPD, Chronic Obstructive Pulmonary Disease; CI, Confidence Intervals; CRC, Colorectal cancer; FAP, Familial Adenomatous Polyposis; $\mathrm{FiO}_{2}$, Fraction of inspiratory oxygen; FFP, Fresh frozen plasma; HC, Hepatic cancer; HIF-1, Hypoxia-inducible factor 1; HR, Hazard Ratio; IORT, IntraOperative Radiation Therapy; $\mathrm{paO}_{2}$, Arterial oxygen pressure; PC, Pancreatic cancer; PLT, Platelet concentrates; Q, Quartile; R 0, No residual tumor; R 1, Microscopic residual tumor; RBC, Red blood cells; RCT, Randomized controlled trial; ROS, Reactive Oxygen Species; SD, Standard Deviation; SE, Standard Error; SSI, Surgical Site Infetions; TNM, Tumor, Node, Metastasis; TU, Transfusion units; UICC, Tumor classification according to the Union for International Cancer Control; WHO, World-Health-Organization.
}

and was approved by the local Ethics Committee of the Medical Faculty of the Ruprecht-Karls-University, Heidelberg (S326/2019, August 9, 2019). We assessed whether perioperative $\mathrm{FiO}_{2}$ was associated with recurrence-free survival after surgery for three exemplary abdominal cancer entities. Patients with elective surgery of the pancreas, colon or rectum, or liver were included. Subgroup analysis was performed for the three tumor entities. Data were retrieved for all patients $\geq 18$ years of age who underwent elective resection of pancreatic (PC), colorectal (CRC,) or hepatic cancer (HC) with R0 (no residual tumor) or R1 (microscopic residual tumor) resection, without distant metastases at the time of surgery, and with followup for at least 180 days. Exclusion criteria were intraoperative detection of peritoneal carcinomatosis or if histology analysis could not reveal cancer tissue i.e., after neoadjuvant chemo- or radiotherapy. Patients were also excluded if they suffered familial adenomatous polyposis or did receive home oxygen therapy in the preoperative period.

\section{Data Collection}

Baseline data retrieved from the prospectively maintained electronic pancreas, colorectal, and liver databases of the Department of Surgery at Heidelberg, University Hospital and from the electronic patient file were: demographic data, weight, height, body mass index (BMI), American Society of Anesthesiologists physical status classification (ASA), preexisting diseases including diabetes mellitus and chronic obstructive pulmonary disease (COPD), history of smoking, duration of surgery, need for postoperative ventilation, reintubation, use of epidural anesthesia, intraoperative dose of sufentanil, units of red blood cells (RBC), fresh frozen plasma (FFP), and platelet concentrates (PLT) transfused during surgery and during the entire hospital stay, use of intraoperative radiation therapy (IORT), neoadjuvant and adjuvant radio-, and chemotherapy. For colorectal and pancreatic cancer, tumor site was differentiated as follows: pancreatic head vs. body/tail cancer and rectal vs. colon cancer. Resection margin status, TNM (tumor, node, metastasis) classification, and tumor grading were retrieved from pathology reports. For every patient mean $\mathrm{FiO}_{2}$ was calculated on the basis of the $\mathrm{FiO}_{2}$ levels documented in the anesthesia protocol at 15-min intervals after induction of anesthesia (first $45 \mathrm{~min}$ ) until extubation. Furthermore, the measurements of partial pressure of oxygen in arterial blood gases $\left(\mathrm{paO}_{2}\right)$ during surgery were collected. For outcome analyses, intensive care unit and hospital length of stay, date of local recurrence or occurrence of distant metastases, and date and cause of death were collected.

\section{Outcome Analysis}

The primary outcome measure was recurrence-free survival in the period from index surgery until the last known followup. Recurrence-free survival was defined as the time from index surgery to the first documented event of local cancer recurrence, newly diagnosed metastases, or death. Computer tomography, abdominal ultrasound, physical examination, and blood sampling were conducted in follow-up examinations at regular intervals or were prompted by new symptoms. If there 
was no diagnosis of cancer recurrence, new metastases, or death documented, the last date of follow-up or doctor-patient contact with negative findings was recorded. Secondary outcomes were overall survival, sepsis, reoperations due to surgical complications, SSI (superficial incisional, deep incisional, and organ space) and cardiovascular events (myocardial infarction, cerebral infarction, or transitory ischemic attack) during hospital stay were recorded.

\section{Statistical Analysis}

The entire patient cohort was sorted based on ascending mean intraoperative $\mathrm{FiO}_{2}$ values and was then divided into two equal sized groups. The low $-\mathrm{FiO}_{2}$ group and the high $-\mathrm{FiO}_{2}$ group comprised 542 patients each. Descriptive analyses comprised calculation of mean, standard deviation (SD), median, and first and third quartile for continuous variables and absolute and relative proportions for categorical variables. The distribution of categorical variables in the different groups was compared using the chi-square test. Differences in continuous variables were evaluated using the Mann-Whitney $U$ test. The primary survival analysis for the prespecified primary endpoint recurrence-free survival was performed using the Kaplan-Meier method (16) and groups were compared by means of the log-rank test (17). As the three tumor entities were not equally distributed over the low- and high- $\mathrm{FiO}_{2}$ groups, and because the tumor entities analyzed in our study differed regarding long-term survival rates, we performed an additional analysis to control for tumor entity. First, within each of the three tumor entities, patients were sorted by ascending intraoperative mean $\mathrm{FiO}_{2}$ values before patients were equally divided into a low- and high$\mathrm{FiO}_{2}$ group within each entity. Kaplan-Meier curves of these groups were compared within entities. Then patients from the three-tumor entity specific low- $\mathrm{FiO}_{2}$ groups were combined into one-entity-controlled low- $\mathrm{FiO}_{2}$ group, and patients from the three-tumor entity specific high- $\mathrm{FiO}_{2}$ groups were combined in one entity-controlled high- $\mathrm{FiO}_{2}$ group. These two groups were compared using a stratified log-rank test with the different tumor entities as strata. Thereafter, the primary outcome was analyzed within the tumor entities PC and CRC by the Cox proportional hazard model (18) in which the effect of mean $\mathrm{FiO}_{2}$ on recurrence-free survival adjusted for the following covariates was estimated: gender, age, body mass index, nicotine use, diabetes mellitus, UICC (Tumor classification according to the Union for International Cancer Control) stage, tumor localization, tumor grading, resection margin status, use of epidural anesthesia, intraoperative dose of sufentanil, units of RBC, FFP, and PLT transfused during the entire hospital stay, intraoperative, neoadjuvant and adjuvant radio- and chemotherapy, and laparoscopic surgery in patients with CRC. If fentanyl was used as the opiate instead of sufentanil, the fentanyl dose was multiplied by a factor of 0.1 to calculate the equivalent sufentanil dose (19).

Mean $\mathrm{FiO}_{2}$, age, PLT transfusion, intraoperative dose of sufentanil, and BMI are continuous variables, and the other variables are categorial. $P$-values of regression coefficients were obtained by the Wald-Test. Hazard ratios (HRs) estimated from the Cox analysis were reported with corresponding 95\% CIs and a two-sided $p<0.05$ was denoted as considerable. The HC-stratum was too small to fit a covariate-adjusted cox regression. The 1year and 5-year overall survival was estimated by the KaplanMeier method. $P$-value is referred to the stratified log rank test with entities as strata.

Statistical analyses were performed using IBM SPSS Statistics 26.0 (SPSS, Chicago, IL) and Prism 9.0.0 (GraphPad Prism Software, Inc, San Diego, CA).

\section{RESULTS}

Data from 1,214 patients were retrieved from databases. Datasets from 100 patients could not be assessed for eligibility because of incomplete or missing anesthesia records since the patient ID retrieved from the database did not match with a case in the hospital information system, or because the type of surgery was not eligible, i.e., non-tumor surgery. Considering exclusion criteria, 30 patients had to be excluded. Therefore, 1,084 patients were included in the final analysis set (Figure 1) with a median follow-up of 3.28 (Q1-Q3, 1.68-4.97) years.

\section{Patient Characteristics}

Main clinical and demographical baseline characteristics are presented in Table 1 and the Supplementary Material. A total of 1,084 patients underwent elective PC $(n=652)$, CRC $(n=$ $405)$, or HC surgery $(n=27)$. The mean age was $63 \pm 11$ years. Male participants were slightly more than female participants. At the time of surgery, the most common cancer stage was UICC 2 and the most common tumor grades were 1 and 2. Around $45 \%$ of patients' tumor resection margin status in the pathology report was classified as $\mathrm{R} 1$. In the majority of patients with PC, "pancreatic head" was found as the tumor localization; in the majority of patients with CRC "rectum" was found as the tumor localization. Patients received neoadjuvant chemotherapy or neoadjuvant radiotherapy in $15 \%$ of cases and $70 \%$ received adjuvant chemotherapy. IORT was conducted in 3\%. General anesthesia was performed as balanced anesthesia except in four patients. In a small proportion (four patients (0.3\%)), fentanyl was used instead of sufentanil and the corresponding equivalent dose was calculated. Intraoperative dose of sufentanil was slightly higher in the low- $\mathrm{FiO}_{2}$-groups of patients with $\mathrm{CRC}$ and PC (CRC: $88.45 \mu \mathrm{g} \pm 45.04$ vs. $80.12 \mu \mathrm{g} \pm 32.37$; low vs. high$\mathrm{FiO}_{2}, p=0.012$; PC: $80.86 \mu \mathrm{g} \pm 51.16$ vs. $72.22 \mu \mathrm{g} \pm 42.85$; low vs. high- $\mathrm{FiO}_{2}, p=0.002 ; \mathrm{HC}: 73.21 \mu \mathrm{g} \pm 42.23$ vs. 66.92 $\mu \mathrm{g} \pm 27.80$; low- vs. high- $\mathrm{FiO}_{2}, p=1.0$ ). Epidural anesthesia was more common in the high- $\mathrm{FiO}_{2}$-groups of patients with CRC and PC (CRC: 21(10\%) vs. 39 (19\%); low- vs. high- $-\mathrm{FiO}_{2}$, $p=0.011$; PC: 230 (71\%) vs. 258 (79\%); low- vs. high- $\mathrm{FiO}_{2}$, $p=0.011$; HC: $10(71 \%)$ vs. $10(77 \%), p=0.745)$. In total, $111(10.2 \%)$ patients were transfused intraoperatively and 284 (26.2\%) during their entire hospital stay. There was no difference between the entity-controlled low- $\mathrm{FiO}_{2}$ and entity-controlled high- $\mathrm{FiO}_{2}$ groups (intraoperative transfusion: 54 (9.9\%) vs. 57 (10.5\%); entity-controlled low- $\mathrm{FiO}_{2}$ vs. entity-controlled high$\mathrm{FiO}_{2} ; p=0.784$; transfusions during entire hospital stay: 139 


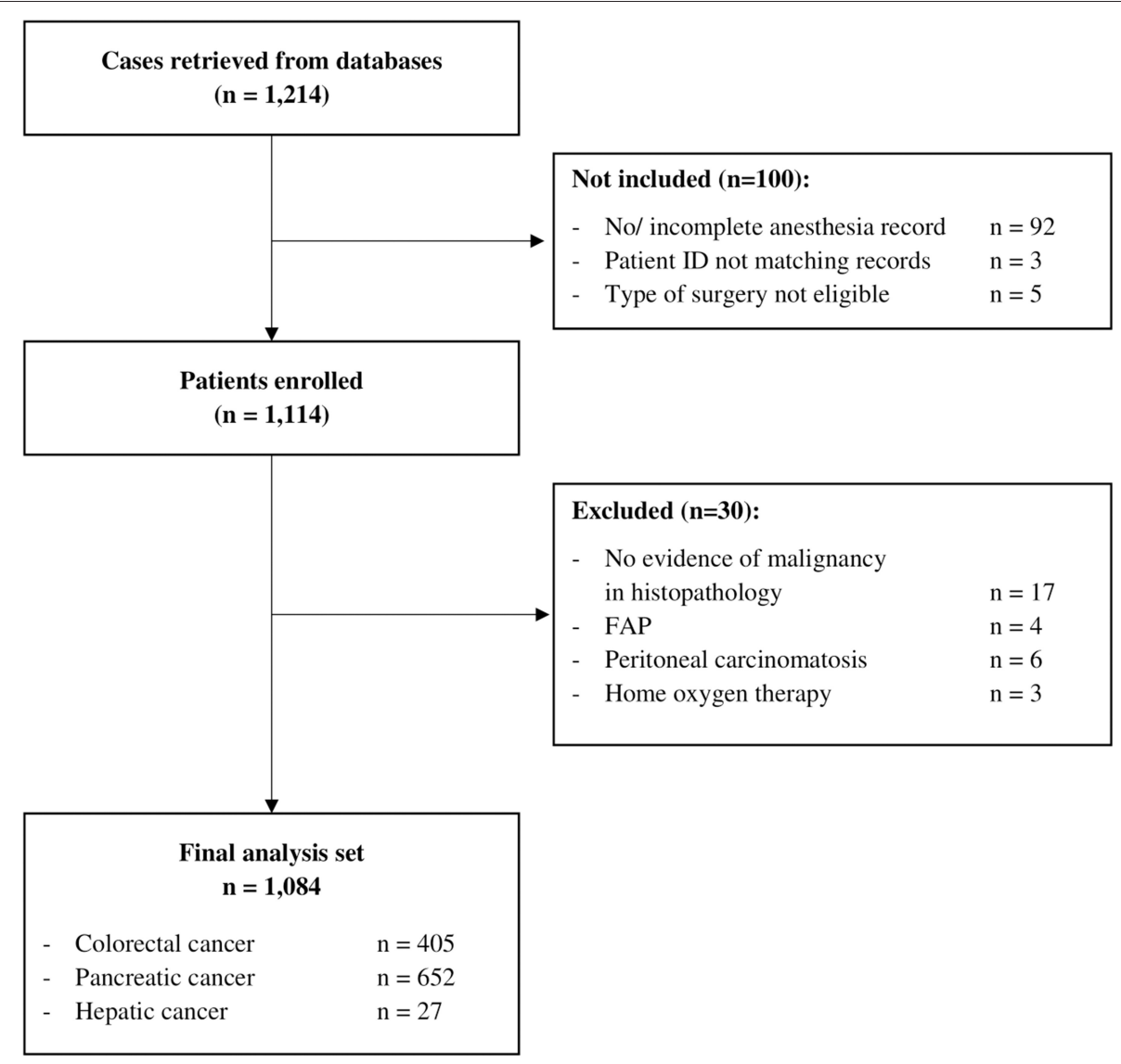

FIGURE 1 | Participant flow chart.

(25.6\%) vs. 145 (26.8\%); entity-controlled low- $\mathrm{FiO}_{2}$ vs. entitycontrolled high- $\left.\mathrm{FiO}_{2} ; p=0.652\right)$.

The average age was higher in the low- $-\mathrm{FiO}_{2}$ group (64 \pm 10.5 vs. $62 \pm 11$ years, low- vs. high- $\mathrm{FiO}_{2}, p=0.003$ ). For none of the tumor entities, differences with regard to diabetes, history of smoking, or gender were detected. Also, for neither of the tumor entities we observed differences regarding tumor grading status, UICC stage, resection margin status, neoadjuvant, adjuvant therapy, or IORT. In PC surgery, tumor localization in the pancreatic head was more common in the low- $\mathrm{FiO}_{2}$ group ( 81 vs. $72 \%, p=0.009$; low- vs. high- $\mathrm{FiO}_{2}$ ). There was no difference in CRC patients with regard to tumor localization between both groups. In CRC surgery, open surgery was more common in the high- $\mathrm{FiO}_{2}$ group ( 85 vs. $92 \%, p=0.029$; lowvs. high- $-\mathrm{FiO}_{2}$ ). $\mathrm{PC}$ and $\mathrm{HC}$ surgery were always performed as open surgery. Robotic surgery was not performed in our patient cohort. The proportions of the three tumor entities differed between the low and high- $\mathrm{FiO}_{2}$ group (PC: $72.1 \%$, CRC: $26.8 \%$, HC: $1.1 \%$ vs. PC $48.2 \%$, CRC $48.0 \%$, HC $3.9 \%$, $p<0.001$; low- vs. high-- $\mathrm{FiO}_{2}$ ). The average duration of $\mathrm{PC}$ surgery was longer than the duration of $\mathrm{CRC}$ and $\mathrm{HC}$ surgery (PC:313 min \pm 103 , CRC $221 \mathrm{~min} \pm 83$, HC: $168 \mathrm{~min} \pm 69$, $p<0.001)$.

\section{Observed $\mathrm{FiO}_{2}$ and $\mathrm{PaO}_{2}$}

After dividing the cohort into low and high $\mathrm{FiO}_{2}$ patients, the cut off value between the two groups was $45.1 \%$, the median of patients' intraoperative $\mathrm{FiO}_{2}$ mean [Q1; Q3] in the low- $\mathrm{FiO}_{2}$ group was 40.9 [38.3; 42.9] vs. 50.4\% [47.4; 54.7] in the high- $\mathrm{FiO}_{2}$ group (Figure 2A). In CRC surgery, the calculated cut off value was $48.1 \%$, the median of patients' $\mathrm{FiO}_{2}$ means in the low- $\mathrm{FiO}_{2}$ group was $42.8[40.0 ; 45.6]$ vs. $53.1 \%[50.3 ; 58.6]$ in the high- $\mathrm{FiO}_{2}$ group. In PC surgery, the calculated cut off value was $43.6 \%$, the median of patients' $\mathrm{FiO}_{2}$ means in the low- $-\mathrm{FiO}_{2}$ group was 39.8 [37.7; 41.8] vs. $47.9 \%[45.5 ; 52.1]$ in the high $-\mathrm{FiO}_{2}$ group. In $\mathrm{HC}$ surgery, the calculated cut off value was $54.0 \%$, the median of patients' $\mathrm{FiO}_{2}$ means in the low- $\mathrm{FIO}_{2}$ group was 45.5 [41.0; 47.9] vs. $60.2 \%[56.1 ; 62.8]$ in the high $-\mathrm{FiO}_{2}$ group (Figure 2B).

The mean $\mathrm{paO}_{2}$ during surgery was significantly higher in the high- $\mathrm{FiO}_{2}$ group (median of patients' intraoperative $\mathrm{paO}_{2}$ mean: $172.7 \mathrm{mmHg}$ [152.15; 193.05] vs. $200.7 \mathrm{mmHg}$ [173.2; 235.8], low-vs. high- $\mathrm{FiO}_{2}$ ) (Figure 3A). After stratifying for tumor entities, median $\mathrm{paO}_{2}$ values were also significantly lower in the low- $\mathrm{FiO}_{2}$ groups compared to the high- $\mathrm{FiO}_{2}$ groups (CRC: Median of patients' intraoperative $\mathrm{paO}_{2}$ mean: $167.9 \mathrm{mmHg}$ [146.5; 188.0] vs. $190.0 \mathrm{mmHg}$ [147.0; 217.5], low-vs.high- $\mathrm{FiO}_{2}$; PC: Median of patients' intraoperative $\mathrm{paO}_{2}$ mean: $172.38 \mathrm{mmHg}$ 
TABLE 1 | Clinical baseline characteristics of the study cohort.

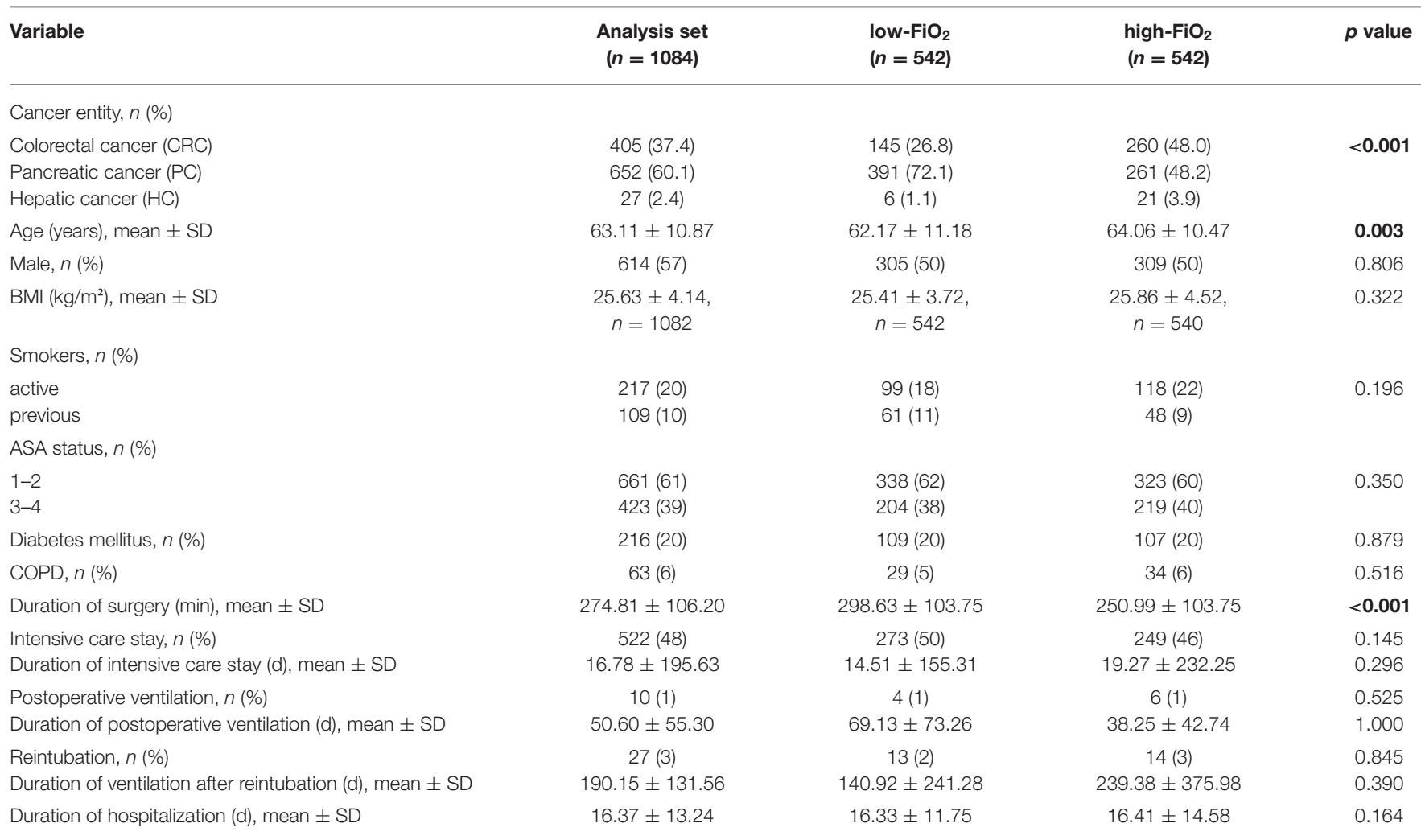

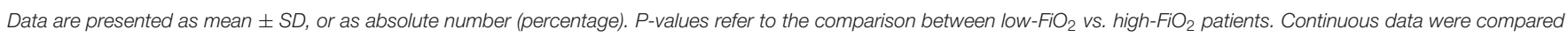

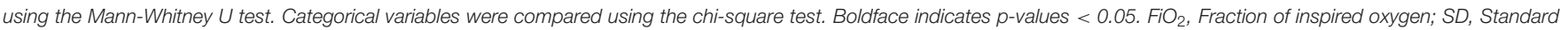
deviation; BMI, Body mass index; ASA, risk classification according to the American Society of Anesthesiologists; COPD, Chronic obstructive pulmonary disease.

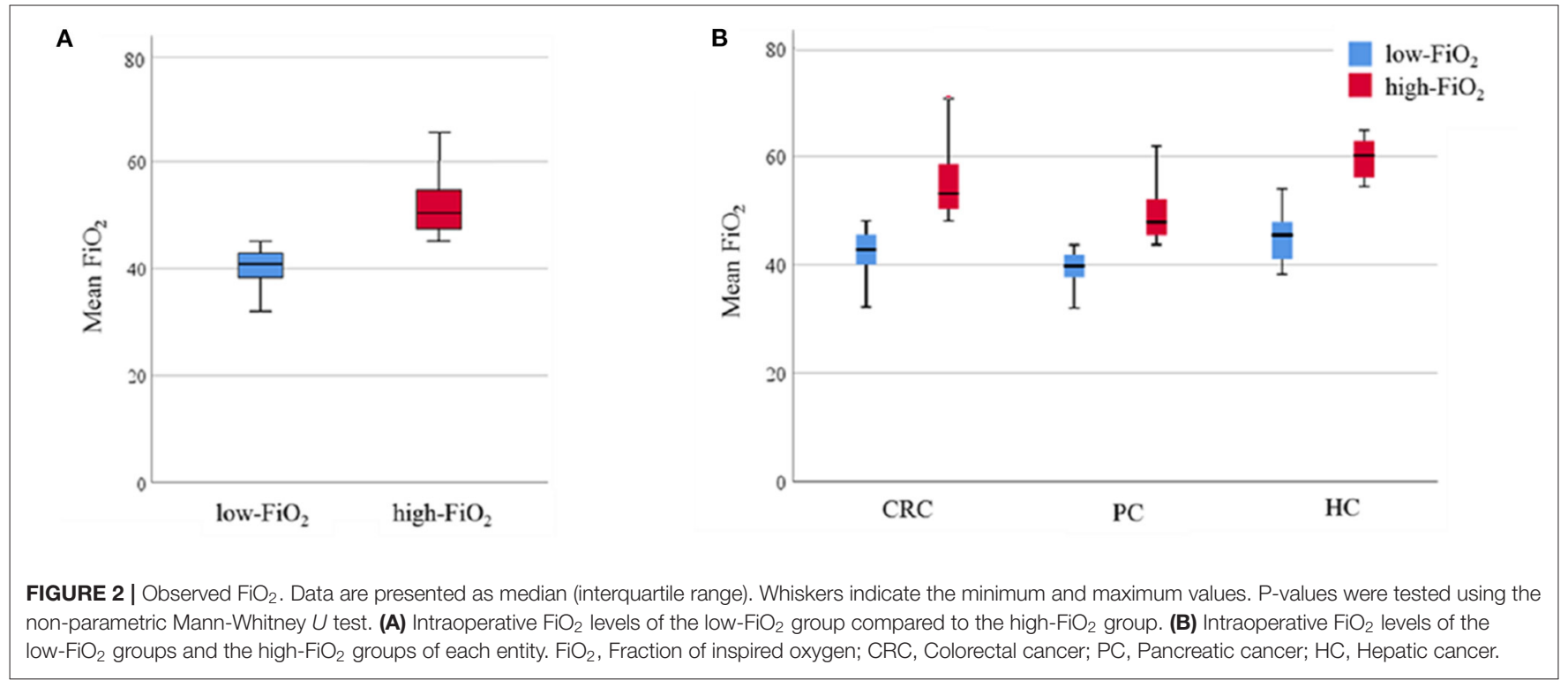

[152.6; 190.3] vs. $203.4 \mathrm{mmHg}$ [174.1; 230.0], low-vs. high- $\mathrm{FiO}_{2}$; $\mathrm{HC}$ : Median of patients' intraoperative $\mathrm{paO}_{2}$ mean: $197.0 \mathrm{mmHg}$ [162.3; 214.3] vs. 238.33 mmHg [198.3; 296.4], low-vs. high- $\mathrm{FiO}_{2}$ ) (Figure 3B).

\section{Survival Analysis}

In total, cancer recurrence between index surgery and last follow-up was diagnosed in 588 patients (54\%). Among those patients, $136(23.1 \%)$ experienced local recurrence and no 

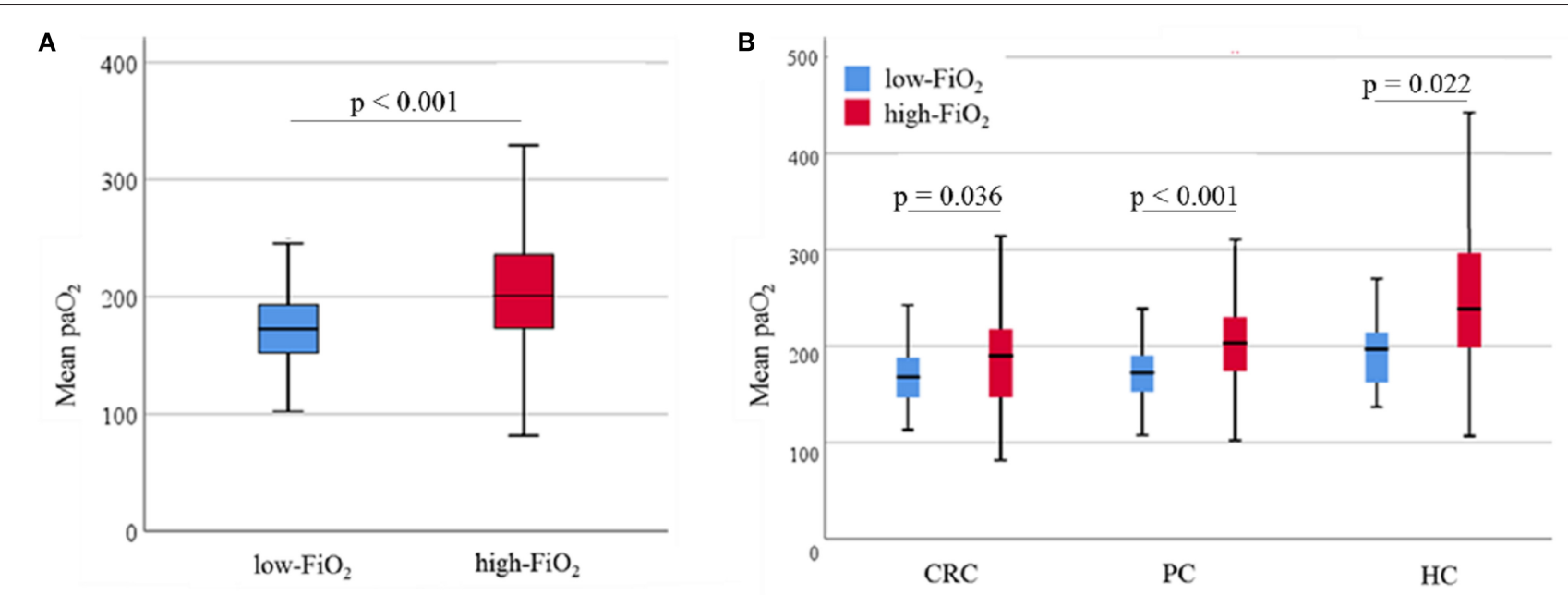

FIGURE 3 | Observed $\mathrm{paO}_{2}$. Data are presented as median (interquartile range). Whiskers indicate the minimum and maximum values. $P$-values were tested using the non-parametric Mann-Whitney $U$ test. (A) Intraoperative mean $\mathrm{paO}_{2}$ levels of the low- $\mathrm{FiO}_{2}$ group compared to the high- $\mathrm{FiO} 2$ group. (B) Intraoperative mean paO 2 levels of the low $-\mathrm{FiO}_{2}$ groups and the high- $\mathrm{FiO}_{2}$ groups of each entity. $\mathrm{paO}_{2}$, Arterial oxygen pressure; $\mathrm{CRC}, \mathrm{Colorectal}$ cancer; $\mathrm{PC}$, Pancreatic cancer; $\mathrm{HC}, \mathrm{Hepatic}$ cancer.

distant metastases, 309 (52.5\%) had distant metastases without local recurrence, and 133 patients (22.6\%) suffered from both local relapse and distant metastases. For 10 patients (1.7\%), information about the type of recurrence was not available. During the observation period, 402 patients (37.1\%) died, mostly (381 cases) due to their malignant disease. Two patients died due to postoperative complications; four patients because of cardiovascular events after hospital discharge. In 15 patients, the cause of death was unknown. Recurrence-free survival was considerably higher in the high- $\mathrm{FiO}_{2}$ group (log-ranktest: $p<0.001$ ) (Figure 4). This effect was preserved in the entity-controlled groups. Recurrence-free survival was lower in the entity-controlled -low- $\mathrm{FiO}_{2}$ group compared to the entitycontrolled -high- $\mathrm{FiO}_{2}$ group (stratified log rank test: $p=0.007$ ) (Figure 5).

The cancer entity itself plays a relevant role in the average survival time of a patient (20-22). Therefore, we performed subgroup analyses for PC and CRC patients respectively using a Cox proportional hazard model, considering factors influencing the observed effect. These analyses revealed an independent association for mean $\mathrm{FiO}_{2}$ and recurrence-free survival in patients undergoing $\mathrm{CRC}$ surgery $(\mathrm{B}=-0.035$; $p=0.025)$. Recurrence-free survival was longer in patients with higher mean $\mathrm{FiO}_{2}$. The hazard ratio (HR) for the variable mean $\mathrm{FiO}_{2}$ was 0.965 , and thus, $\mathrm{HR}$ is $0.965^{5}=$ 0.837 between two patients whose mean $\mathrm{FiO}_{2}$ differ by $5 \%$; per $1 \%$ rise of mean $\mathrm{FiO}_{2}$ the hazard for the primary outcome decreases by 3.5\% ( $\operatorname{Exp}(B): 0.965 ; 95 \%$ CI:0.9360.996) (Table 2). There was no evidence for an association of $\mathrm{FiO}_{2}$ mean with recurrence-free survival in patients undergoing PC surgery $(\mathrm{B}=-0.01 ; \operatorname{Exp}(\mathrm{B})=0.990 ; \mathrm{CI}: 0.975-1.01 ; p=$ 0.217 ) (Table 3 ). Because the $\mathrm{HC}$ group consists of 27 patients only, it was not considered suitable for an individual Cox regression analysis.

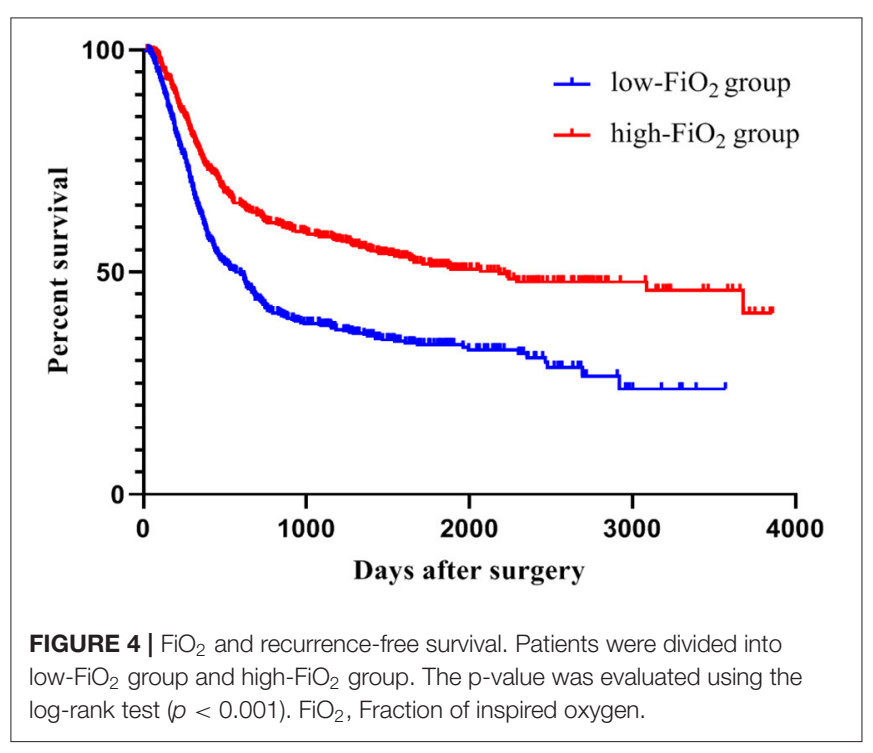

\section{Secondary Endpoints}

We examined 1-year and 5-year survival rates in patients with CRC, PC, and HC separately. In CRC patients, 1-year survival was $100 \%$ in both the low- and the high- $\mathrm{FiO}_{2}$ group. After 5 years, five out of 203 patients had died (5-year survival 96.2\%) in the low- $\mathrm{FiO}_{2}$ group, whereas eight out of 202 patients had died in the high- $-\mathrm{FiO}_{2}$ group (5-year survival 94.6\%). In PC patients, 39 out of 326 patients had died after 1 year (1-year survival $87.9 \%$ ) in the low- $-\mathrm{FiO}_{2}$ group, whereas in the high- $-\mathrm{FiO}_{2}$ group 43 out of 326 patients had died (1-year survival 86.7\%). After 5 years, 188 patients in the low- $\mathrm{FiO}_{2}$ group had died (5-year survival $36.0 \%$ ) vs. 183 patients in the high- $-\mathrm{FiO}_{2}$ group (5-year survival $38.5 \%)$. In HC patients, 1-year and 5-year survival was $100 \%$ in 

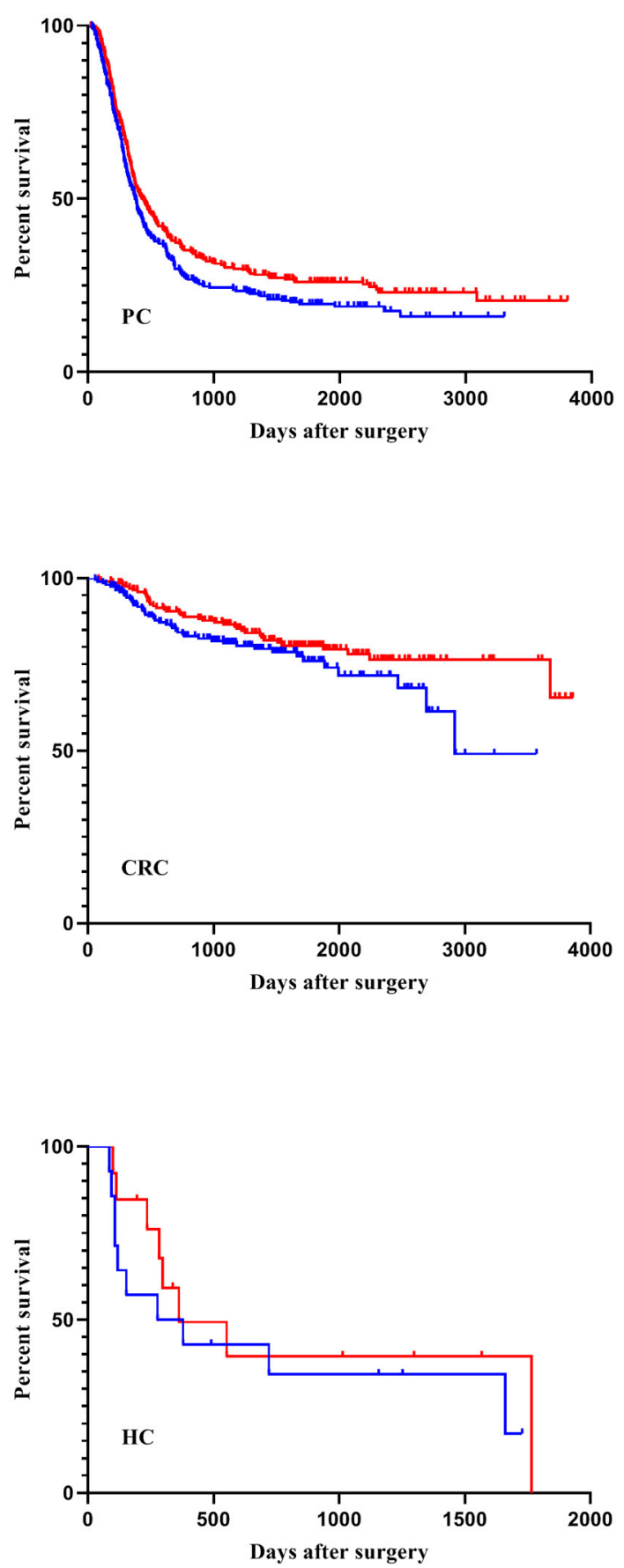

FIGURE 5 | $\mathrm{FiO}_{2}$ and recurrence-free survival stratified for tumor entities. Patients were divided into an entity-controlled low- $\mathrm{FiO}_{2}$ group and entity-controlled high- $\mathrm{FiO}_{2}$ group. A stratified log-rank test with entities as strata was performed $(p=0.007)$. $\mathrm{FiO}_{2}$, Fraction of inspired oxygen; $\mathrm{CRC}$, Colorectal cancer; PC, Pancreatic cancer; HC, Hepatic cancer.

both the low-and the high- $\mathrm{FiO}_{2}$ group. Neither 1- nor 5-year survival was different between the entity-controlled low- $\mathrm{FiO}_{2}$ and entity-controlled high- $\mathrm{FiO}_{2}$ group $(p=0.525)$ (Table 4).
Cardiovascular events ( 5 vs. 5 , low-vs. high-FiO $2, p=1$ ) and incidence of sepsis ( 5 vs. 6 , low- vs. high- $\mathrm{FiO}_{2}, p=0.76$ ) did not differ between groups. There was no difference in the rate of SSI (61 vs. 55 , low-vs. high- $\mathrm{FiO}_{2}, p=0.556$ ), and the occurrence of reoperations was not different ( 40 vs. $36, p=0.634$, low-vs. high-FiO 2 ) (Table 4).

\section{DISCUSSION}

In this retrospective exploratory study, we demonstrated in a real-world setting that higher intraoperative $\mathrm{FiO}_{2}$ during abdominal cancer surgery was associated with better recurrencefree survival. In CRC surgery, higher $\mathrm{FiO}_{2}$ was independently associated with increased recurrence-free survival. The hazard for the primary outcome decreased by $3.5 \%$ with every $1 \%$ increase in $\mathrm{FiO}_{2}$. In PC surgery, we did not observe a significant effect and we did not find differences in any of the secondary endpoints.

The patient cohort under investigation had undergone surgery before the first WHO recommendation advocating supplemental oxygen for prevention of SSI (13) was published. Therefore, the decision for a specific $\mathrm{FiO}_{2}$ was a clinical decision mainly based on the patients' respiratory function and the anesthetists' preference.

Oxygen has known pro- and anticarcinogenic effects. Hyperoxia may not only cause direct cell damage through the generation of reactive oxygen species (ROS) but also mediates cancerous effects $(12,23,24)$, such as promotion of proliferation, invasiveness, angiogenesis, and metastasis. Interestingly, ROS generation may be accelerated under hyperoxia and also hypoxia (14). In addition, hypoxia can lead to organ dysfunction, lactic acidosis, cell death (25), and an increased expression of the hypoxia-inducible factor 1 (HIF-1) $(26,27)$ an intrinsic survival factor of tumor cells. Therefore, hypoxia can induce a vast number of gene products that control neovascularization, cell survival, energy metabolism, intracellular $\mathrm{pH}$, and cell migration and are often associated with increased tumor aggressiveness, therapeutic resistance, and mortality $(26,28-31)$.

In clinical studies, evidence for $\mathrm{FiO}_{2}$-mediated effects associated with long-term outcome after abdominal cancer surgery is sparse and controversial. In a post-hoc analysis of the PROXI trial, cancer-free survival was significantly shorter in the high oxygen group (12). In line, after a median followup of 2.3 years, a subsequent analysis of the same trial found increased long-term mortality in patients receiving $80 \%$ oxygen during cancer surgery (11). Contrarily, authors of other post-hoc analysis, combining mortality data from different RCTs, found that there was neither a difference in long-term mortality nor did they find differences in overall survival for patients randomly assigned to $30 \%$ vs. $80 \% \mathrm{FiO}_{2}(32,33)$. The median follow-up was $12.8(3.8,13.6)$ years in the trial by Greif, $4.3(3.6,4.8)$ years in the trial by Kurz, and $3.2(0.5,4.9)$ years in the study by Jiang $(1,33,34)$. This is in line with our finding that overall survival did not differ between high and low $\mathrm{FiO}_{2}$ groups with a median follow-up of $3.28(1.68,4.97)$ years. Although $\mathrm{FiO}_{2}$ appears to affect cancer recurrence, follow-up in our study might have 
TABLE 2 | Independent effects of $\mathrm{FiO}_{2}$ on recurrence-free survival in patients with CRC.

\begin{tabular}{|c|c|c|c|c|c|c|}
\hline & \multirow[t]{2}{*}{ B } & \multirow[t]{2}{*}{ SE } & \multirow[t]{2}{*}{ Sig. } & \multirow[t]{2}{*}{$\operatorname{Exp}(B)$} & \multicolumn{2}{|c|}{$95 \% \mathrm{Cl}$ for $\operatorname{Exp}(\mathrm{B})$} \\
\hline & & & & & Lower & Upper \\
\hline Female Sex & 0.273 & 0.285 & 0.339 & 1.314 & 0.751 & 2.299 \\
\hline Age at time of surgery (y) & 0.014 & 0.011 & 0.217 & 1.014 & 0.992 & 1.037 \\
\hline BMl $\left(\mathrm{kg} / \mathrm{m}^{2}\right)$ & 0.046 & 0.031 & 0.144 & 1.047 & 0.984 & 1.113 \\
\hline No smoking (reference) & & & 0.062 & & & \\
\hline Former smoking & 0.254 & 0.409 & 0.534 & 1.290 & 0.578 & 2.875 \\
\hline Current smoking & 0.684 & 0.293 & 0.019 & 1.982 & 1.117 & 3.516 \\
\hline Diabetes mellitus & -0.244 & 0.380 & 0.521 & 0.784 & 0.372 & 1.650 \\
\hline Dose of sufentanil & 0.004 & 0.003 & 0.222 & 1.004 & 0.998 & 1.009 \\
\hline Epidural anesthesia & 0.300 & 0.381 & 0.432 & 1.350 & 0.639 & 2.849 \\
\hline No RBC (reference) & & & 0.962 & & & \\
\hline RBC (1-5 TU) & 0.285 & 0.382 & 0.456 & 1.329 & 0.629 & 2.809 \\
\hline RBC (6-10 TU) & -13.14 & 710.33 & 0.985 & 0.000 & 0.000 & . \\
\hline RBC (11-15 TU) & -0.194 & 1.036 & 0.852 & 0.824 & 0.108 & 6.276 \\
\hline RBC (>15 TU) & -10.03 & 882.63 & 0.991 & 0.000 & 0.000 & . \\
\hline PLT (TU) & -10.43 & 287.61 & 0.971 & 0.000 & 0.000 & $1.922 E+240$ \\
\hline No FFP (reference) & & & 0.994 & & & \\
\hline FFP (1-5 TU) & -0.084 & 0.778 & 0.914 & 0.919 & 0.200 & 4.227 \\
\hline FFP (>5 TU) & -12.55 & 1210.6 & 0.992 & 0.000 & 0.000 & . \\
\hline Laparoscopic surgery & 0.009 & 0.422 & 0.983 & 1.009 & 0.441 & 2.307 \\
\hline UICC stage 0-1 (reference) & & & 0.000 & & & \\
\hline UICC stage 2 & 1.394 & 0.522 & 0.008 & 4.031 & 1.449 & 11.213 \\
\hline UICC stage 3 & 2.440 & 0.524 & 0.000 & 11.468 & 4.104 & 32.044 \\
\hline Grading G 1-2 (reference) & & & 0.062 & & & \\
\hline No grading due to neoadjuvant therapy & -1.102 & 0.549 & 0.045 & 0.332 & 0.113 & 0.975 \\
\hline Grading G 3-4 & -0.655 & 0.447 & 0.143 & 0.519 & 0.216 & 1.247 \\
\hline Resection margin status R1 & 1.132 & 0.642 & 0.078 & 3.102 & 0.882 & 10.907 \\
\hline Rectal cancer & -0.063 & 0.306 & 0.837 & 0.939 & 0.515 & 1.711 \\
\hline Neoadjuvant chemotherapy & 1.261 & 0.481 & 0.009 & 3.529 & 1.375 & 9.060 \\
\hline Neoadjuvant radiotherapy & 0.279 & 0.572 & 0.626 & 1.321 & 0.431 & 4.053 \\
\hline IORT & 2.152 & 1.140 & 0.059 & 8.605 & 0.921 & 80.377 \\
\hline Adjuvant therapy & 0.270 & 0.299 & 0.366 & 1.310 & 0.729 & 2.352 \\
\hline Mean $\mathrm{FiO}_{2}$ & -0.035 & 0.016 & 0.025 & 0.965 & 0.936 & 0.996 \\
\hline
\end{tabular}

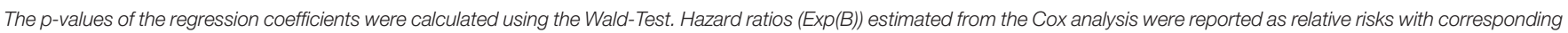

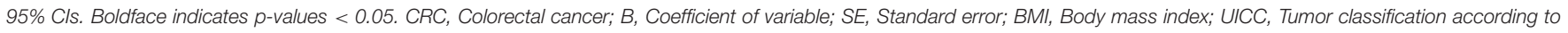

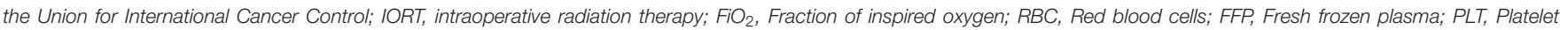
concentrates; TU, Transfusion units.

been too short to observe effects on mortality after recurrence. Also, overall survival did not differ between the two groups investigated here, probably because overall survival depends on a variety of other factors not assessed in this study.

In most prospective studies, comparing different $\mathrm{FiO}_{2}$ concentrations, patients were randomized for either 30 or $80 \% \mathrm{FiO}_{2}$. However, both targets have been accused to cause considerable side effects. Outside of clinical trials and before guidelines advocating high levels of supplemental oxygen were published, most anesthetists chose moderate $\mathrm{FiO}_{2}$ levels between the high and low extremes. As a result, in our retrospective study, mean $\mathrm{FiO}_{2}$ levels in the low- and high$\mathrm{FiO}_{2}$ groups were closer together than in other studies. Importantly, our institutional standards suggest avoiding not only hypoxia but also hyperoxia as both conditions might cause adverse events.

Pro and anticarcinogenic effects of oxygen might explain why, on one hand, $80 \% \mathrm{FiO}_{2}$ has adverse effects over $30 \% \mathrm{FiO}_{2}$ in some studies, but on the other hand, in our study, $\mathrm{FiO}_{2}$ in the range of $50 \%$ compared with lower $\mathrm{FiO}_{2}$ concentrations was beneficial with regard to recurrence-free survival. It is conceivable that the optimal $\mathrm{FiO}_{2}$ for tumor surgery patients is neither met with an $\mathrm{FiO}_{2}$ of $30 \%$ nor $80 \%$. In fact, the association of $\mathrm{FiO}_{2}$ or $\mathrm{paO}_{2}$ respectively and recurrence-free survival may follow a V-shaped curve.

Oxygen related effects in tumor biology may also differ for distinct types of tumors. The association of tumor-associated transcription factors and tumor progress varies among different 
TABLE 3 | Independent effects of $\mathrm{FiO}_{2}$ on recurrence-free survival in patients with PC.

\begin{tabular}{|c|c|c|c|c|c|c|}
\hline & \multirow[t]{2}{*}{ B } & \multirow[t]{2}{*}{ SE } & \multirow[t]{2}{*}{ Sig. } & \multirow[t]{2}{*}{$\operatorname{Exp}(B)$} & \multicolumn{2}{|c|}{$95 \% \mathrm{Cl}$ for $\operatorname{Exp}(\mathrm{B})$} \\
\hline & & & & & Lower & Upper \\
\hline Female Sex & -0.014 & 0.097 & 0.884 & 0.986 & 0.815 & 1.192 \\
\hline Age at time of surgery $(\mathrm{y})$ & -0.003 & 0.005 & 0.491 & 0.997 & 0.987 & 1.006 \\
\hline BMI $\left(k g / m^{2}\right)$ & -0.018 & 0.013 & 0.175 & 0.983 & 0.958 & 1.008 \\
\hline No smoking (reference) & & & 0.730 & & & \\
\hline Former smoking & -0.112 & 0.171 & 0.514 & 0.894 & 0.639 & 1.251 \\
\hline Current smoking & -0.069 & 0.128 & 0.589 & 0.933 & 0.726 & 1.200 \\
\hline Diabetes mellitus & 0.012 & 0.115 & 0.915 & 1.012 & 0.808 & 1.268 \\
\hline Dose of sufentanil & 0.001 & 0.001 & 0.194 & 1.001 & 0.999 & 1.003 \\
\hline Epidural anesthesia & -0.076 & 0.120 & 0.527 & 0.927 & 0.732 & 1.173 \\
\hline No RBC (reference) & & & 0.722 & & & \\
\hline RBC (1-5 TU) & 0.018 & 0.122 & 0.882 & 1.018 & 0.802 & 1.294 \\
\hline RBC (6-10 TU) & 0.242 & 0.278 & 0.385 & 1.274 & 0.738 & 2.199 \\
\hline RBC (11-15 TU) & -0.526 & 0.553 & 0.341 & 0.591 & 0.200 & 1.746 \\
\hline $\mathrm{RBC}(>15 \mathrm{TU})$ & 0.217 & 0.670 & 0.747 & 1.242 & 0.334 & 4.619 \\
\hline PLT (TU) & 0.236 & 0.225 & 0.295 & 1.266 & 0.814 & 1.968 \\
\hline No FFP (reference) & & & 0.454 & & & \\
\hline FFP (1-5 TU) & 0.218 & 0.200 & 0.278 & 1.243 & 0.839 & 1.841 \\
\hline FFP (>5 TU) & 0.381 & 0.425 & 0.370 & 1.464 & 0.637 & 3.363 \\
\hline UICC stage $2 b-3$ & 0.816 & 0.129 & 0.000 & 2.260 & 1.756 & 2.909 \\
\hline Grading G 1-2 (reference) & & & 0.000 & & & \\
\hline No grading due to neoadjuvant therapy & -0.350 & 0.328 & 0.286 & 0.705 & 0.370 & 1.340 \\
\hline Grading G 3-4 & 0.552 & 0.105 & 0.000 & 1.737 & 1.414 & 2.134 \\
\hline Resection margin status R1 & 0.264 & 0.122 & 0.030 & 1.302 & 1.026 & 1.653 \\
\hline Pancreatic head cancer & -0.362 & 0.119 & 0.002 & 0.696 & 0.552 & 0.878 \\
\hline Neoadjuvant chemotherapy & 0.626 & 0.299 & 0.036 & 1.871 & 1.042 & 3.358 \\
\hline Neoadjuvant radiotherapy & -0.305 & 0.355 & 0.391 & 0.737 & 0.367 & 1.479 \\
\hline IORT & 0.674 & 0.349 & 0.054 & 1.963 & 0.990 & 3.893 \\
\hline Adjuvant therapy & -0.314 & 0.156 & 0.044 & 0.731 & 0.539 & 0.991 \\
\hline Mean $\mathrm{FiO}_{2}$ & -0.010 & 0.008 & 0.217 & 0.990 & 0.975 & 1.006 \\
\hline
\end{tabular}

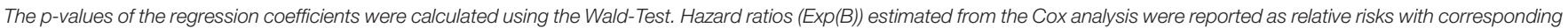

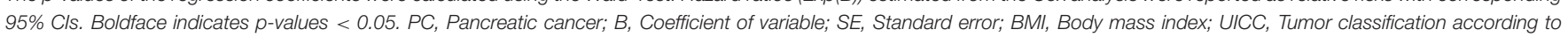

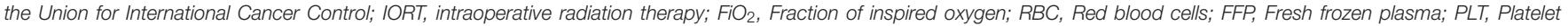
concentrates; TU, Transfusion units.

tumor entities (26). We included patients with CRC, PC, and $\mathrm{HC}$. We demonstrated an independent association of $\mathrm{FiO}_{2}$ with recurrence-free survival for CRC surgery patients but not for patients undergoing PC surgery. Interestingly, Podolyak et al. and Jiang et al. who did not find differences regarding cancerfree survival investigated only patients with elective colectomy in their post-hoc analysis, including RCTs $(32,33)$. In the post-hoc analysis of the PROXI trial, about half the patients underwent colorectal surgery (12). A subgroup analysis for non-colorectal procedures was not conducted, although cancer histology was considered (12).

Additional adverse effects of high- $-\mathrm{FiO}_{2}$ affecting the cardiovascular and respiratory systems have been reported in the literature. Hyperoxia induces increased peripheral vascular resistance, promotes reduced cardiac output, and mediates coronary vasoconstriction $(14,35)$. A post-hoc analysis of the PROXI-trial showed that patients with a
$\mathrm{FiO}_{2}$ of $80 \%$ had a significantly increased risk of myocardial infarction, acute coronary syndrome, or death (36). Contrary, the authors of a systematic review and meta-analysis concluded, based on 17 RCTs and two non-randomized studies, that perioperative supplemental oxygen was not associated with relevant complications (10). Consistent with this report, our analysis did not reveal differences for secondary cardiovascular endpoints or redo surgery.

WHO, ACS (American College of Surgeons), and CDC (Centers for Disease Control and Prevention) recommends supplemental oxygen with the aim to prevent SSI. In our study, SSI did not differ between the high- and low- $-\mathrm{FiO}_{2}$ groups. One could argue that the $\mathrm{FiO}_{2}$ in the high- $-\mathrm{FiO}_{2}$ group was not sufficiently high to prevent SSI. However, the incidence of SSI reported in this study is lower than reported in most of the RCTs testing different oxygen levels in abdominal cancer surgery patients. 
TABLE 4 | Secondary outcome analysis.

\begin{tabular}{|c|c|c|c|}
\hline Overall survival & $\begin{array}{l}\text { Analysis set } \\
(n=1084)\end{array}$ & $\begin{array}{c}\text { Entity-controlled } \\
\text { low-FiO }_{2}(n=543)\end{array}$ & $\begin{array}{l}\text { Entity-contro } \\
\text { high--FiO } 2(n=\end{array}$ \\
\hline \multicolumn{4}{|c|}{ (A) Overall Survival entity-controlled low- $-\mathrm{FiO}_{2}$ group compared to the entity-controlled high- $\mathrm{FiO}{ }_{2} \mathrm{group}$} \\
\hline $\begin{array}{l}\text { CRC: } \\
\text { Number of patients alive after one year (1-year } \\
\text { survival rate in \%) } \\
\text { Number of patients alive after five years (5-year } \\
\text { survival rate in \%) }\end{array}$ & $\begin{array}{c}n=405 \\
405(100) \\
392(96.8)\end{array}$ & $\begin{array}{c}n=\mathbf{2 0 3} \\
203(100) \\
198(97.5)\end{array}$ & $\begin{array}{l}n=\mathbf{2 0 2} \\
202(100) \\
194(96.0)\end{array}$ \\
\hline $\begin{array}{l}\text { PC: } \\
\text { Number of patients alive after one year (1-year } \\
\text { survival rate in \%) } \\
\text { Number of patients alive after five years (5-year } \\
\text { survival rate in \%) }\end{array}$ & $\begin{array}{c}n=652 \\
570(87.4) \\
281(43.1)\end{array}$ & $\begin{array}{c}n=326 \\
287(88.0) \\
138(42.3)\end{array}$ & $\begin{array}{c}n=326 \\
283(86.8) \\
143(43.9)\end{array}$ \\
\hline $\begin{array}{l}\text { HC: } \\
\text { Number of patients alive after one year (1-year } \\
\text { survival rate in \%) }\end{array}$ & $\begin{array}{l}n=27 \\
27(100) \\
27(100)\end{array}$ & $\begin{array}{l}n=14 \\
14(100) \\
14(100)\end{array}$ & $\begin{array}{l}n=13 \\
13(100) \\
13(100)\end{array}$ \\
\hline
\end{tabular}

Number of patients alive after five years (5-year

survival rate in \%)

\begin{tabular}{|c|c|c|c|c|}
\hline Secondary outcome & $\begin{array}{c}\text { Analysis set } \\
(n=1084)\end{array}$ & low-FiO $2(n=542)$ & high-FiO $2(n=542)$ & $p$ value \\
\hline \multicolumn{5}{|c|}{ (B) Other secondary outcomes low- $\mathrm{FiO}_{2}$ group compared to the high- $-\mathrm{FiO}_{2}$ group } \\
\hline Cardiovascular event during hospitalization, $n(\%)$ & $10(0.9)$ & $5(0.9)$ & $5(0.9)$ & 1.000 \\
\hline $\mathrm{SSI}, n(\%)$ & $116(10.7)$ & $61(11.2)$ & $55(10.1)$ & 0.556 \\
\hline Superficial incisional & $60(5.5)$ & $31(5.7)$ & $29(5.4)$ & 0.791 \\
\hline Deep incisional & $4(0.4)$ & $3(0.6)$ & $1(0.2)$ & 0.316 \\
\hline Organ/ space & $52(4.8)$ & $27(5.0)$ & $25(5.0)$ & 0.776 \\
\hline Sepsis, $n(\%)$ & $11(1.0)$ & $5(0.9)$ & $6(1.1)$ & 0.762 \\
\hline Reoperation during hospitalization, $n$ (\%) & $76(7.0)$ & $40(7.4)$ & $36(6.6)$ & 0.634 \\
\hline
\end{tabular}

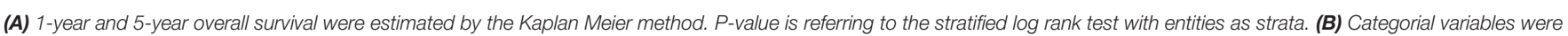

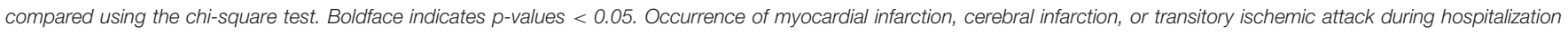
was subsumed as cardiovascular events. $\mathrm{FiO}_{2}$, Fraction of inspired oxygen; SSI, surgical site infection; CRC, Colorectal cancer; PC, Pancreatic cancer.

Our study has some limitations that need to be addressed. We performed a retrospective, single-center study with a limited set of exemplary tumor entities. The number of individuals included in the analysis was limited by the availability of digitalized anesthesia records, and only patients recruited in the surgical databases could be analyzed. The choice of $\mathrm{FiO}_{2}$ values was not standardized and the patients were equally split into the low- and high- $\mathrm{FiO}_{2}$ groups. The patients' intraoperative $\mathrm{FiO}_{2}$ levels were compared by the calculation of the individual mean $\mathrm{FiO}_{2}$, but the duration of exposure and individual dose during surgery were not included in this calculation. A consequence of the retrospective nature of our study is that we do not have full control over confounders. As tumor entity itself affects outcome, and we conducted an analysis stratified for entities and performed a cox regression analysis to control for confounders. However, we cannot fully exclude, that additional confounders affected findings reported in this study.

In conclusion, we demonstrate that, within a moderate range of $\mathrm{FiO}_{2}$, higher $\mathrm{FiO}_{2}$ during abdominal cancer surgery was associated with longer recurrence-free survival. In colorectal cancer surgery, increased $\mathrm{FiO}_{2}$ was independently associated with increased recurrence-free survival. The findings will be instrumental for designing prospective studies delineating effects of certain $\mathrm{FiO}_{2}$ on cancer development and progression for specific patient populations. Until definite evidence from largescale randomized controlled trials is available, anesthesiologist, in the absence of relevant clinical conditions warranting specific $\mathrm{FiO}_{2}$ values, should aim for an intraoperative $\mathrm{FiO}_{2}$ of $50 \%$ in abdominal cancer surgery as this might benefit oncological outcome.

\section{DATA AVAILABILITY STATEMENT}

The data analyzed in this study is subject to the following licenses/restrictions: Datenschutzgrundverordnung. Requests to access these datasets should be directed to jan.larmann@med.uni-heidelberg.de.

\section{ETHICS STATEMENT}

The studies involving human participants were reviewed and approved by Ethics Committee of the Medical Faculty of the Ruprecht-Karls-University, Heidelberg. Written informed consent for participation was not required for 
this study in accordance with the national legislation and the institutional requirements.

\section{AUTHOR CONTRIBUTIONS}

$\mathrm{SD}, \mathrm{VS}, \mathrm{RK}$, and JL designed research and study protocol. SD, VS, LK, SK, and JL formal analysis. JL, SD, and VS statistical analysis. SK methodology and statistical consultation. SD, VS, RK, LK, $\mathrm{KH}, \mathrm{MS}, \mathrm{TH}, \mathrm{MB}$, and MW contributed to the data curation. SD, VS, and JL wrote the first draft of the manuscript. All authors critically reviewed and revised the manuscript and approved the final work.

\section{FUNDING}

This study was funded by institutional resources from the Departments of Anesthesiology and General, Visceral and Transplant Surgery. The position of LK was funded by the German Research Foundation (LA 2343/7-1) to JL. This research

\section{REFERENCES}

1. Greif R, Akça O, Horn EP, Kurz A, Sessler DI. Supplemental perioperative oxygen to reduce the incidence of surgical-wound infection. $N$ Engl J Med. (2000) 342:161-7. doi: 10.1056/NEJM200001203420303

2. Qadan M, Akça O, Mahid SS, Hornung CA, Polk HC. Perioperative supplemental oxygen therapy and surgical site infection: a metaanalysis of randomized controlled trials. Arch Surg. (2009) 144:359-66. doi: 10.1001/archsurg.2009.1

3. Pryor KO, Fahey TJ, Lien CA, Goldstein PA. Surgical site infection and the routine use of perioperative hyperoxia in a general surgical population: a randomized controlled trial. Jama. (2004) 291:79-87. doi: 10.1001/jama.291.1.79

4. de Jonge S, Egger M, Latif A, Loke YK, Berenholtz S, Boermeester M, et al. Effectiveness of $80 \%$ vs $30-35 \%$ fraction of inspired oxygen in patients undergoing surgery: an updated systematic review and meta-analysis. $\mathrm{Br} J$ Anaesth. (2019) 122:325-34. doi: 10.1016/j.bja.2018.11.024

5. Ban KA, Minei JP, Laronga C, Harbrecht BG, Jensen EH, Fry DE, et al. American college of surgeons and surgical infection society: surgical site infection guidelines, 2016 update. J Am Coll Surg. (2017) 224:5974. doi: 10.1016/j.jamcollsurg.2016.10.029

6. Berríos-Torres SI, Umscheid CA, Bratzler DW, Leas B, Stone EC, Kelz $\mathrm{RR}$, et al. Centers for disease control and prevention guideline for the prevention of surgical site infection, 2017. JAMA Surg. (2017) 152:78491. doi: 10.1001/jamasurg.2017.0904

7. WorldHealthOrganization. Global Guidelines for the Prevention of Surgical Site Infection. (C) World Health Organization (2018).

8. Cohen B, Schacham YN, Ruetzler K, Ahuja S, Yang D, Mascha EJ, et al. Effect of intraoperative hyperoxia on the incidence of surgical site infections: a meta-analysis. Br J Anaesth. (2018) 120:1176-86. doi: 10.1016/j.bja.2018. 02.027

9. Smith BK, Roberts RH, Frizelle FA. O(2) No Longer the Go(2): a systematic review and meta-analysis comparing the effects of giving perioperative oxygen therapy of $30 \% \mathrm{FiO}(2)$ to $80 \% \mathrm{FiO}(2)$ on surgical site infection and mortality. World J Surg. (2020) 44:69-77. doi: 10.1007/s00268-019-05224-3

10. Mattishent K, Thavarajah M, Sinha A, Peel A, Egger M, Solomkin J, et al. Safety of $80 \%$ vs $30-35 \%$ fraction of inspired oxygen in patients undergoing surgery: a systematic review and meta-analysis. Br J Anaesth. (2019) 122:31124. doi: 10.1016/j.bja.2018.11.026

11. Meyhoff CS, Jorgensen LN, Wetterslev J, Christensen KB, Rasmussen LS. Increased long-term mortality after a high perioperative inspiratory oxygen did not receive any other specific grants from funding agencies in the public, commercial, or not-for-profit sectors.

\section{ACKNOWLEDGMENTS}

We gratefully acknowledge Ulf Hinz and Biljana Gigic, Department of General, Visceral and Transplant Surgery, University of Heidelberg, Heidelberg, Germany, for their support and co-operation in collecting the data. We also want to express our gratitude to Melanie Wickert, Department of Anesthesiology, University of Heidelberg, Heidelberg, Germany for her administrative support and manuscript editing.

\section{SUPPLEMENTARY MATERIAL}

The Supplementary Material for this article can be found online at: https://www.frontiersin.org/articles/10.3389/fmed. 2021.761786/full\#supplementary-material

fraction during abdominal surgery: follow-up of a randomized clinical trial. Anesth Analg. (2012) 115:849-54. doi: 10.1213/ANE.0b013e3182652a51

12. Meyhoff CS, Jorgensen LN, Wetterslev J, Siersma VD, Rasmussen LS. Risk of new or recurrent cancer after a high perioperative inspiratory oxygen fraction during abdominal surgery. Br J Anaesth. (2014) 113:i7481. doi: $10.1093 /$ bja/aeu110

13. WorldHealthOrganization. Global Guidelines for the Prevention of Surgical Site Infection. Geneva, (2016).

14. Martin DS, Grocott MPIII. Oxygen therapy in anaesthesia: the yin and yang of O2. Br J Anaesth. (2013) 111:867-71. doi: 10.1093/bja/aet291

15. Cuschieri S. The STROBE guidelines. Saudi J Anaesth. (2019) 13:S31s4. doi: 10.4103/sja.SJA_543_18

16. Kaplan EL, Meier P. Nonparametric estimation from incomplete observations. J Am Stat Assoc. (1958) 53:45781. doi: $10.1080 / 01621459.1958 .10501452$

17. Mantel N. Evaluation of survival data and two new rank order statistics arising in its consideration. Cancer Chemother Rep. (1966) 50:163-70.

18. Cox DR. Regression Models and Life-Tables. J R Stat Soc B. (1972) 34:187220. doi: 10.1111/j.2517-6161.1972.tb00899.x

19. Nielsen S, Degenhardt L, Hoban B, Gisev N. A synthesis of oral morphine equivalents (OME) for opioid utilisation studies. Pharmacoepidemiol Drug Saf. (2016) 25:733-7. doi: 10.1002/pds.3945

20. Klaiber U, Schnaidt ES, Hinz U, Gaida MM, Heger U, Hank T, et al. Prognostic factors of survival after neoadjuvant treatment and resection for initially unresectable pancreatic cancer. Ann Surg. (2021) 273:15462. doi: $10.1097 /$ SLA. 0000000000003270

21. Strobel O, Hank T, Hinz U, Bergmann F, Schneider L, Springfeld C, et al. Pancreatic cancer surgery: the new r-status counts. Ann Surg. (2017) 265:56573. doi: $10.1097 /$ SLA. 0000000000001731

22. Ulrich CM, Gigic B, Böhm J, Ose J, Viskochil R, Schneider M, et al. The colocare study: a paradigm of transdisciplinary science in colorectal cancer outcomes. Cancer Epidemiol Biomarkers Prev. (2019) 28:591601. doi: 10.1158/1055-9965.EPI-18-0773

23. Selvendiran K, Kuppusamy ML, Ahmed S, Bratasz A, Meenakshisundaram $\mathrm{G}$, Rivera BK, et al. Oxygenation inhibits ovarian tumor growth by downregulating STAT3 and cyclin-D1 expressions. Cancer Biol Ther. (2010) 10:386-90. doi: 10.4161/cbt.10.4.12448

24. Nishida N, Arizumi T, Takita M, Kitai S, Yada N, Hagiwara S, et al. Reactive oxygen species induce epigenetic instability through the formation of 8hydroxydeoxyguanosine in human hepatocarcinogenesis. Dig Dis. (2013) 31:459-66. doi: 10.1159/000355245 
25. Schneider M, Weitz J. Acute oxygen deprivation and hypoxia tolerance. Dtsch Med Wochenschr. (2008) 133:2168-72. doi: 10.1055/s-0028-1091258

26. Mabjeesh NJ, Amir S. Hypoxia-inducible factor (HIF) in human tumorigenesis. Histol Histopathol. (2007) 22:559-72.

27. Ni J, Wang X, Stojanovic A, Zhang Q, Wincher M, Bühler L, et al. SingleCell RNA sequencing of tumor-infiltrating NK cells reveals that inhibition of transcription factor HIF- $1 \alpha$ unleashes NK cell activity. Immunity. (2020) 52:1075-87.e8. doi: 10.1016/j.immuni.2020.05.001

28. Hirota K, Semenza GL. Regulation of angiogenesis by hypoxiainducible factor 1. Crit Rev Oncol Hematol. (2006) 59:1526. doi: 10.1016/j.critrevonc.2005.12.003

29. Semenza GL. Targeting HIF-1 for cancer therapy. Nat Rev Cancer. (2003) 3:721-32. doi: 10.1038/nrc1187

30. Ruan K, Song G, Ouyang G. Role of hypoxia in the hallmarks of human cancer. J Cell Biochem. (2009) 107:1053-62. doi: 10.1002/jcb.22214

31. Milano M, Schneider M. EPO in cancer anemia: benefits and potential risks. Crit Rev Oncol Hematol. (2007) 62:11925. doi: 10.1016/j.critrevonc.2006.11.011

32. Podolyak A, Sessler DI, Reiterer C, Fleischmann E, Akça O, Mascha EJ, et al. Perioperative supplemental oxygen does not worsen long-term mortality of colorectal surgery patients. Anesth Analg. (2016) 122:190711. doi: 10.1213/ANE.0000000000001316

33. Jiang Q, Kurz A, Zhang X, Liu L, Yang D, Sessler DI. Supplemental intraoperative oxygen and long-term mortality: subanalysis of a multiple crossover cluster trial. Anesthesiology. (2021) 134:709-21. doi: 10.1097/ALN.0000000000003694

34. Kurz A, Fleischmann E, Sessler DI, Buggy DJ, Apfel C, Akça O. Effects of supplemental oxygen and dexamethasone on surgical site infection: a factorial randomized trial. Br J Anaesth. (2015) 115:434-43. doi: 10.1093/bja/aev062
35. Wijesinghe M, Perrin K, Ranchord A, Simmonds M, Weatherall M, Beasley R. Routine use of oxygen in the treatment of myocardial infarction: systematic review. Heart. (2009) 95:198-202. doi: 10.1136/hrt.2008. 148742

36. Fonnes S, Gögenur I, Søndergaard ES, Siersma VD, Jorgensen LN, Wetterslev J, et al. Perioperative hyperoxia - Long-term impact on cardiovascular complications after abdominal surgery, a post hoc analysis of the PROXI trial. Int J Cardiol. (2016) 215:238-43. doi: 10.1016/j.ijcard.2016. 04.104

Conflict of Interest: The authors declare that the research was conducted in the absence of any commercial or financial relationships that could be construed as a potential conflict of interest.

Publisher's Note: All claims expressed in this article are solely those of the authors and do not necessarily represent those of their affiliated organizations, or those of the publisher, the editors and the reviewers. Any product that may be evaluated in this article, or claim that may be made by its manufacturer, is not guaranteed or endorsed by the publisher.

Copyright (c) 2021 Dehne, Spang, Klotz, Kummer, Kilian, Hoffmann, Schneider Hackert, Büchler, Weigand and Larmann. This is an open-access article distributed under the terms of the Creative Commons Attribution License (CC BY). The use, distribution or reproduction in other forums is permitted, provided the original author(s) and the copyright owner(s) are credited and that the original publication in this journal is cited, in accordance with accepted academic practice. No use, distribution or reproduction is permitted which does not comply with these terms. 